\title{
BMJ Open Primary care patient and practitioner views of weight and weight-related discussion: a mixed-methods study
}

\author{
Calum T McHale (D) , Anita H Laidlaw (D) , Joanne E Cecil (D)
}

To cite: McHale CT, Laidlaw AH, Cecil JE. Primary care patient and practitioner views of weight and weightrelated discussion: a mixedmethods study. BMJ Open 2020;10:e034023. doi:10.1136/ bmjopen-2019-034023

- Prepublication history for this paper is available online. To view these files, please visit the journal online (http://dx.doi. org/10.1136/bmjopen-2019034023).

Received 09 September 2019 Revised 11 February 2020 Accepted 12 February 2020

\section{Check for updates}

(C) Author(s) (or their employer(s)) 2020. Re-use permitted under CC BY-NC. No commercial re-use. See rights and permissions. Published by BMJ.

School of Medicine, University of St Andrews, St Andrews, UK

Correspondence to

Calum T McHale;

ctm2@st-andrews.ac.uk

\section{ABSTRACT}

Objective To understand the beliefs that primary care practitioners (PCPs) and patients with overweight and obesity have about obesity and primary care weight management in Scotland.

Setting Seven National Health Service (NHS) Scotland primary care centres.

Participants A total of 305 patients and 14 PCPs (12 general practitioners; two practice nurses) participated. Design and methodology A cross-sectional mixed-methods study. PCPs and patients completed questionnaires assessing beliefs about obesity and primary care weight communication and management Semi-structured interviews were conducted with PCPs to elaborate on questionnaire topics. Quantitative and qualitative data were synthesised to address study objectives.

Results (1) Many patients with overweight and obesity did not accurately perceive their weight or risk of developing weight-related health issues; (2) PCPs and patients reported behavioural factors as the most important cause of obesity, and medical factors as the most important consequence; (3) PCPs perceive their role in weight management as awareness raising and signposting, not prevention or weight monitoring; (4) PCPs identify structural and patient-related factors as barriers to weight communication and management, but not PCP factors. Conclusions Incongruent and/or inaccurate beliefs held by PCPs and patient may present barriers to effective weight discussion and management in primary care. There is a need to review, standardise and clarify primary care weight management processes in Scotland. Acknowledging a shared responsibility for obesity as a disease may improve outcomes for patients with overweight and obesity.

\section{INTRODUCTION}

Excess body weight is among the most serious global public health challenges of the $21 \mathrm{st}$ century. ${ }^{1}$ Currently, 39\% (1.9 billion) of the global adult population have overweight and $13 \%$ (650 million) have obesity. ${ }^{2}$ The UK has among the highest prevalence of overweight and obesity in the world, ${ }^{3}$ and in Scotland, $65 \%$ of the adult Scottish population have overweight and $29 \%$ have obesity. ${ }^{4}$

Approximately, 24.2 million National Health Service (NHS) primary care

\section{Strengths and limitations of this study}

This study addresses an important knowledge gap regarding the weight-related beliefs of primary care practitioners (PCPs) and patients in Scotland.

- All participating patients were consulted by one of the participating PCPs, allowing more meaningful interpretations of the data.

- The patient sample was representative in terms of prevalence of overweight and obesity in the Scottish population.

- Practice nurses were challenging to engage and therefore under-represented in this sample.

consultations occur annually in Scotland ${ }^{5}$ and patients with obesity consult primary care more frequently than healthy weight patients. ${ }^{6}$ UK clinical guidelines state that primary care has a key role in identifying and monitoring overweight and obesity in the patient population and providing weight management if necessary. ${ }^{7} 8$ Thus, primary care has the potential to support patients with overweight and obesity to manage their weight. Despite this, observational and self-report evidence conclude that weight issues are seldom discussed with patients with overweight and obesity in primary care consultations, and weight management is not routinely offered to patients with overweight and obesity. ${ }^{9-11}$

Primary care practitioners (PCPs) often perceive patient weight as challenging to manage and cite multiple weight management barriers, including time/resource constraints, poor patient motivation, concerns about upsetting patients and lack of weight-related training. ${ }^{12-14}$ Self-report research suggests that many PCPs and patients hold negative, biassed and incongruent views about the aetiology of obesity, about people with overweight and obesity and about the role of primary care in weight management. ${ }^{15-17}$ Evidence shows that many individuals who have clinical overweight or obesity often 
underestimate their weight ${ }^{18-20}$ and the risk that excessive weight has for their health. ${ }^{21}$ Beliefs about health issues play a key role in health behaviour change models (eg, Health Action Process Approach ${ }^{22}$ ): for example inaccurate weight perceptions can reduce the willingness of people with overweight and obesity to engage in weight management. ${ }^{23}$ Research investigating medical practitioner (including PCP) weight-related beliefs and care outcomes for patient with obesity concluded that biased and stigmatising practitioner views may result in poor quality care for patients with obesity. ${ }^{24}$ Thus, beliefs and perceptions from both PCPs and patients may present barriers to effective weight management in primary care.

Much of the existing research examining the beliefs of PCPs and patients about weight management in primary care is non-UK based. One study examining PCPs beliefs about weight management in Scotland found PCPs were unenthusiastic about delivering weight management to patients with overweight and obesity. ${ }^{25}$ Recent survey research with 107 PCPs working in Scotland reported that PCPs believe limited resources, poor patient motivation and lack of previous success presented significant barriers. ${ }^{26}$ To our knowledge, no research has examined both PCPs' and their patients' weight-related beliefs in Scotland. Given the extent of the overweight problem in Scotland and the potential primary care has to facilitate weight management, it is important to investigate weightrelated beliefs and perceptions of PCPs and patients and consider what implications these have for weight management in primary care. This study investigates the beliefs of PCPs and patients with overweight and obesity about weight and weight management.

Specifically, we sought to understand the following:

1. How do patients with overweight and obesity perceive their weight and their risk of weight-related health issues?

2. Do PCPs and patients share the same beliefs about the causes and consequences of obesity?

3. How do PCPs perceive their role in the management of overweight and obesity?

4. What do PCPs believe are the barriers to weight discussion and management in primary care consultation?

\section{METHODS}

\section{Study design and procedure}

This study was part of a larger $\mathrm{PhD}$ research programme investigating weight-related communication during routine primary healthcare communication, that collected data via video capture, questionnaires and interviews. This paper reports on the questionnaire and interview data. See McHale $e t a l^{11}$ for analysis of video capture data. The research focus on weight-related communication was not disclosed to any participants (PCP or patient) until all video recording was completed in each practice and each participant had completed the questionnaire. During recruitment, participants were initially told that the study was investigating general primary care communication practices. This approach was adopted to avoid biassing routine consultation discussions towards weight-related issues. All participants received a debrief after their participation was completed, which disclosed the research focus on weight and explained that they could withdraw considering this disclosure.

Questionnaires assessing beliefs about obesity and primary care weight management were completed by a convenience sample of PCPs and patients in seven primary care practices across three NHS Scotland health boards (Fife, Lothian and Tayside). PCPs (general practitioners (GPs) and practice nurses (PNs)) also completed semi-structured interviews exploring their weight-related views in greater detail. All participating patients were consulted by one of the participating PCPs.

A convergent mixed-methods design was employed, whereby questionnaire and interview data were concurrently collected, analysed and merged to comprehensively interpret the results. ${ }^{27}$ Patient questionnaires were completed immediately following a routine consultation with one of the participating PCPs. PCP questionnaires were completed following the conclusion of all patient data collection per practice. Patient body mass index (BMI) was calculated from measured height $(\mathrm{m})$ and weight $(\mathrm{kg})$, assessed by the researcher before completing the questionnaire. PCP BMI was calculated from selfreported height and weight in the PCP questionnaire. The decision to collect self-reported height and weight from PCPs (as opposed to direct measurement) was taken to minimise the salience of weight issues as part of the overall approach to avoid biassing routine consultation discussion towards weight-related issues.

The main purpose in conducting semi-structured interviews with PCPs was to provide further understanding and depth to PCPs beliefs measured in questionnaires. Consistent with a concurrent triangulation mixed-methods approach, qualitative and quantitative data were collected during the same research phase, and subsequently analysed and interpreted together to develop a greater understanding of PCP beliefs. ${ }^{27} 28$ Semi-structured interviews were selected for this study because they maintain a guiding structure for participants, yet offer the flexibility to meaningfully diverge or pursue a discussion topic in greater detail. $^{29}$

\section{Data collection}

Patients' gender, age, weight perceptions, ${ }^{30}$ weightrelated disease risk perceptions ${ }^{31}$ and beliefs about the causes and consequences of overweight and obesity ${ }^{32}$ were assessed by questionnaire. Patients' medical notes and histories were not accessed for this study. The PCP questionnaire assessed gender, age and beliefs about the causes, consequences and treatments of overweight and obesity. ${ }^{32}$ The PCP questionnaire also included the Communication on Overweight and Obesity Project (CO-OP) questionnaire, ${ }^{26}$ which assessed PCPs' attitudes towards individuals with overweight and obesity, perceptions of responsibility to manage patient weight, current 
weight management practices and perceived barriers to weight management.

The PCP interview schedule was designed to expand on topics covered in the PCP questionnaire; perceptions of overweight and obesity as a problem in Scotland, the role of primary care in weight management, their current weight management practice, weight-related communication and barriers to weight-related communication in primary care. All interviews occurred face-to-face in PCP's offices immediately following questionnaire completion and were audio recorded. Interviews lasted an average of $22 \mathrm{~min}$ and ranged from $12 \mathrm{~min}$ to $32 \mathrm{~min}$. Due to the format of data collection within primary care practices, it would have been difficult to interview patients without risking disclosure of the research focus on weight-related discussion to practice staff, PCPs and/or other patients. Therefore, patients were not interviewed during this study.

\section{Data analysis}

Descriptive analysis of questionnaire data included calculation of means and SD. Chi-square analysis tested relationships between the weight perceptions and risk perceptions of patients with overweight and obesity. T-tests assessed differences in beliefs about causes and consequences of obesity within patient and PCP groups. Patient BMI classification (healthy weight, overweight and obesity as defined by the $\mathrm{WHO})^{33}$ was included as a between-groups variable to assess whether perceptions differed according to patient BMI classification. Less than 3\% of patient questionnaire data were missing; an Missing Completely At Random (MCAR) test ${ }^{34}$ indicated that these data were missing completely at random $\left(\chi^{2}=3307.68\right.$ (3192), $\left.\mathrm{p}>0.05\right)$. Multiple imputation (MI) was conducted to replace missing responses from patient questionnaires. Descriptive statistics were calculated before MI and all inferential statistics were calculated after MI. MI was not conducted with PCP questionnaire data as only one response was missing in the entire data set. Questionnaire data analysis was conducted using SPSS V.24.

Semi-structured interviews were transcribed and thematic analysis was conducted. The interview schedule was organised into a thematic framework. The five discussion topics within the interview schedule included (1) practitioners' perceptions of overweight and obesity as a problem in Scotland; (2) perceptions about the role of primary care in weight management; (3) current weight management practices; (4) thoughts about weight-related communication with patients with overweight and obesity; (5) thoughts about barriers to weight-related communication in primary care. A semantic essentialist/realist approach was taken when interpreting the dialogue in the interview transcripts, in which themes were constructed based on the explicit surface meaning of the data. ${ }^{35}$ Furthermore, themes and subthemes were deductively coded and were not constructed purely on the basis of prevalence within the data. For example, focus was sometimes given to opinions that differed significantly from other PCPs, and PNs' dialogue was sometimes concentrated on to determine their potentially different perspectives on weight discussion and management. NVivo V.11.4 was used to manage this analysis. ${ }^{36}$

\section{Patient and public involvement (PPI)}

These was no patient or public involvement in this research.

\section{RESULTS}

\section{Sample characteristics}

In total, 305 primary care patients and 14 PCPs (12 GPs; two PNs) participated in this study (table 1). Of these, 218 patients $(71.5 \%)$ and seven PCPs $(50 \%)$ had overweight $\left(\mathrm{BMI} \geq 25 \mathrm{~kg} / \mathrm{m}^{2}\right)$.

How do patients with overweight and obesity perceive their weight and risk of weight-related health issues?

Approximately, $20 \%$ of patients with an obesity BMI classification described their weight as obese, and $54 \%$ of patients with an overweight BMI classification described their weight as overweight (table 2). Comparably, $84 \%$ of patients with a healthy weight BMI classification perceived their weight as healthy. Most patients with overweight $(61 \%)$ and obesity $(88.2 \%)$ perceived their weight to be at least a slight problem, compared with $26.4 \%$ of patients with a healthy weight (table 2).

The perceived risk of developing type 2 diabetes, cardiovascular/heart disease and joint/back pain was lower in patients with an overweight BMI classification who perceived their weight to be a healthy weight, compared with patients with an overweight BMI classification who perceived their weight to be overweight (table 3).

\section{Do PCPs and patients share the same beliefs about the causes} and consequences of obesity?

Concordance was observed between PCP and patient self-reported beliefs about the causes and consequences of obesity. Patients scored behavioural factors (eg, overeating, poor diet, lack of exercise) as significantly more important for causing obesity than medical $(\mathrm{t}(304)=21.18$, $\mathrm{p}<0.001)$, psychological $(\mathrm{t}(304)=14.70, \quad \mathrm{p}<0.001) \quad$ or social $(\mathrm{t}(304)=15.71, \mathrm{p}<0.001)$ factors. PCPs also scored behavioural factors as significantly more important than medical $(\mathrm{t}(13)=9.28, \mathrm{p}<0.001)$, psychological $(\mathrm{t}(13)=8.27$, $\mathrm{p}<0.001)$ or social $(\mathrm{t}(14)=4.76, \mathrm{p}<0.001)$ factors for causing obesity.

Patients scored medical factors (eg, hypertension, diabetes, rheumatism) as significantly more important consequences of obesity than psychological $(\mathrm{t}(304)=5.75$, $\mathrm{p}<0.001)$ and social $(\mathrm{t}(304)=20.61, \mathrm{p}<0.001)$ factors. Mean PCP scores for medical consequences were significantly higher than social scores $(\mathrm{t}(13)=4.95, \mathrm{p}<0.001)$. 
Table 1 Sample characteristics

\begin{tabular}{|c|c|c|c|}
\hline & $\begin{array}{l}\text { Patients } \\
(n=305)\end{array}$ & $\begin{array}{l}\text { GPs } \\
(n=12)\end{array}$ & $\begin{array}{l}\text { Practice nurses } \\
(\mathrm{n}=2)\end{array}$ \\
\hline \multicolumn{4}{|l|}{ Gender, $n(\%)$} \\
\hline Female & $166(54.4)$ & $4(33.3)$ & $2(100)$ \\
\hline Male & $139(45.6)$ & $8(66.7)$ & 0 \\
\hline \multicolumn{4}{|l|}{ Age, $n(\%)$} \\
\hline $18-34$ & $70(23)$ & 1(9) & 0 \\
\hline $35-54$ & $67(22)$ & $11(91)$ & $2(100)$ \\
\hline $55-74$ & $137(45)$ & 0 & 0 \\
\hline $75+$ & $31(10)$ & 0 & 0 \\
\hline \multicolumn{4}{|l|}{$\operatorname{BMI}\left(\mathrm{kg} / \mathrm{m}^{2}\right)$} \\
\hline mean (range) & $28.75(18.9 ; 61.9)^{*}$ & 24.66(22.6; 26.7)† & 26.56(23.2; 29.9)† \\
\hline \multicolumn{4}{|l|}{ BMI classification, $n(\%) \ddagger$} \\
\hline Healthy weight (18.5-24.9) & $87(28.5)$ & $6(50)$ & $1(50)$ \\
\hline Overweight (25-29.9) & $124(40.8)$ & $6(50)$ & $1(50)$ \\
\hline Obesity ( $\geq 30)$ & $94(30.7)$ & 0 & 0 \\
\hline Class I (30-34.9) & $55(58.5)$ & & \\
\hline Class 2 (35-39.9) & $23(24.5)$ & & \\
\hline Class $3(\geq 40)$ & $16(17.0)$ & & \\
\hline
\end{tabular}

${ }^{*}$ Calculated from measured height and weight.

†Calculated from self-reported height and weight $\ddagger \mathrm{BMI}$ classification taken from WHO definitions. ${ }^{33}$

$\mathrm{BMI}$, body mass index; GPs, general practitioners.

How do PCPs perceive their role in the management of overweight and obesity?

Most PCPs agreed with questionnaire statements that PNs $(85.7 \%)$ and GPs $(71.4 \%)$ had an essential role in identifying and treating patients with overweight and obesity, and that patients were well-aware of the health risk of overweight and obesity (table 4 ). Few PCPs believed that PNs' (28.6\%) and GPs' (14.3\%) time was best spent working on obesity prevention; however, few believed that the role of GPs $(21.4 \%)$ and PNs (14.3\%) was to refer patients with

Table 2 Patient perceptions of own weight and weight as a problem

\begin{tabular}{|c|c|c|c|c|c|c|}
\hline & \multicolumn{6}{|c|}{ Patient BMI classification, $\mathrm{n}(\%)^{*}$} \\
\hline & $\begin{array}{l}\text { Healthy weight } \\
(n=87)\end{array}$ & $\begin{array}{l}\text { Overweight } \\
(n=124) \dagger\end{array}$ & Obesity & & & \\
\hline \multicolumn{2}{|l|}{ Patient perceived weight } & & $\begin{array}{l}\text { Class 1f } \\
(n=54)\end{array}$ & $\begin{array}{l}\text { Class } 2 \\
(n=23)\end{array}$ & $\begin{array}{l}\text { Class } 3 \\
(n=16)\end{array}$ & $\begin{array}{l}\text { Overall } \\
(n=94) \ddagger\end{array}$ \\
\hline Underweight & $7(8)$ & 0 & 0 & 0 & 0 & 0 \\
\hline Healthy weight & 73(83.9) & $57(46)$ & $4(7.5)$ & 0 & 0 & $4(4.3)$ \\
\hline Overweight & $7(8)$ & $67(54)$ & $47(87)$ & 15(65.2) & $9(56.3)$ & $71(75.5)$ \\
\hline Obesity & 0 & 0 & $3(5.5)$ & $8(34.8)$ & $7(43.7)$ & $18(19.1)$ \\
\hline \multicolumn{7}{|c|}{ Patient perception of weight as a problem } \\
\hline Not a problem at all & 64(73.6) & $48(39)$ & $9(16.7)$ & $1(4.3)$ & $1(6.3)$ & $11(11.8)$ \\
\hline A slight problem & 18(20.7) & 63(51.2) & $22(40.7)$ & $5(21.7)$ & $2(12.4)$ & 29(31.2) \\
\hline A problem & $2(2.3)$ & $11(8.9)$ & $20(37)$ & $14(61)$ & $9(56.3)$ & $43(45.7)$ \\
\hline A serious problem & $3(3.4)$ & $1(0.8)$ & $3(5.6)$ & $3(13)$ & $4(25)$ & $10(10.8)$ \\
\hline
\end{tabular}

*BMI classification taken from WHO definitions. ${ }^{33}$

†One response missing from the perceptions of weight as a problem.

†One response missing from perceived weight.

$\mathrm{BMI}$, body mass index. 
Table 3 Risk perceptions of developing weight-related health conditions in the future of patients with overweight (BMI 25+) by patient weight perceptions

\section{Likelihood of}

developing health

condition in the future $\chi^{2}$

\begin{tabular}{|c|c|c|c|}
\hline \multicolumn{4}{|l|}{ Health condition } \\
\hline Weight perception & Unlikely & Likely & \\
\hline Diabetes & & & $<0.001^{*}$ \\
\hline Healthy weight & 52 & 3 & \\
\hline Overweight & 98 & 43 & \\
\hline Cancer & & & $>0.05$ \\
\hline Healthy weight & 34 & 20 & \\
\hline Overweight & 78 & 61 & \\
\hline Hypertension & & & $>0.05$ \\
\hline Healthy weight & 28 & 14 & \\
\hline Overweight & 57 & 51 & \\
\hline CVD/heart disease & & & $<0.05^{*}$ \\
\hline Healthy weight & 40 & 17 & \\
\hline Overweight & 70 & 69 & \\
\hline Joint/back pain & & & $<0.05^{*}$ \\
\hline Healthy weight & 18 & 17 & \\
\hline Overweight & 30 & 68 & \\
\hline Asthma & & & $>0.05$ \\
\hline Healthy weight & 40 & 10 & \\
\hline Overweight & 112 & 20 & \\
\hline
\end{tabular}

*Statistically significant.

BMI, body mass index; CVD, cardiovascular disease.

overweight and obesity onto other health professionals. Most PCPs reported that PNs (69.2\%) and GPs (78.6\%) should maintain a healthy weight and act as role models for patients (table 4).

Interview data revealed that GPs and PNs had differing views about the perceived role of primary care in patient weight management. GPs varied in their views about what their role should be and how much responsibility primary care should take for patient weight. Addressing patient weight issues and awareness raising was perceived by most GPs as a professional responsibility, particularly when patients' excessive weight was impacting directly on their health or when patients requested assistance with their weight (table 5; Quotation 1).

Some GPs did not believe their role was to engage patients in preventative weight management or to monitor patient weight during weight loss attempts, articulating that prevention and monitoring were not an efficient use of their time and that standalone weight issues were the responsibility of the patient, not primary care (table 5; Quotations 2 and 3).

PN participants perceived direct weight management as part of their role and reported regularly engaging
Table 4 PCPs attitudes towards patients with overweight and role in weight management

Question

$\mathrm{N}$ agreed

(\%)

Primary care in the treatment of overweight and obesity

Practice nurses have an essential role in $12(85.7)$ identifying and treating overweight and obese patients

GPs have an essential role in identifying and 10 (71.4) treating overweight and obese patients

Treating overweight and obese patients is 8 (57.2) professionally gratifying

I feel well prepared to manage overweight and 9 (64.3) obese patients

GPs' time would be best spent in this area by

$2(14.3)$ preventing overweight and obesity in the first place

Obesity is a disease

Practice nurses' time would be best spent in 4 (28.6) this area by preventing overweight and obesity in the first place

I do not like treating overweight or obese 0 patients

Treatment for weight loss should be offered only to adults who are obese (not overweight)

I do not believe that I can have any effect on patients' ability to lose weight

Overweight and obese patients are usually $\quad 1(7.1)$ quite motivated about lifestyle change

I would only offer advice regarding weight 2 (14.3) control when a patient requests it

Difficulties of weight loss

It is very difficult for overweight and obese

patients to lose weight, no matter what support they are given

Only a small percentage of overweight and

obese patients can lose weight and maintain this loss

GPs' role is to refer overweight and obese patients to other professionals rather than $3(21.4)$ attempt to treat them themselves

Practice nurses' role is to refer overweight and 2 (14.3) obese patients to other professionals rather than attempt to treat them themselves

\begin{tabular}{|c|c|}
\hline \multicolumn{2}{|l|}{ Impacts of health professionals' weight } \\
\hline $\begin{array}{l}\text { I feel my own weight affects how my } \\
\text { overweight/obese patients view my advice }\end{array}$ & $11(78.6)$ \\
\hline $\begin{array}{l}\text { GPs should be role models and maintain } \\
\text { normal weight }\end{array}$ & $11(78.6)$ \\
\hline $\begin{array}{l}\text { Practice nurses should be role models and } \\
\text { maintain normal weight* }\end{array}$ & $9(69.2)$ \\
\hline \multicolumn{2}{|l|}{ Attitudes towards overweight patients } \\
\hline $\begin{array}{l}\text { Most overweight and obese patients are well } \\
\text { aware of the health risks of obesity }\end{array}$ & $11(78.6)$ \\
\hline
\end{tabular}

Continued 


\section{Table 4 Continued}

Question

$\mathrm{N}$ agreed

\begin{tabular}{lc} 
Question & (\%) \\
\hline $\begin{array}{l}\text { I do not experience any barriers to treating } \\
\text { overweight and obese patients }\end{array}$ & $4(28.6)$ \\
I am reluctant to mention weight as I do not & $1(7.1)$ \\
want to make patients feel uncomfortable & \\
Weight loss and health & $14(100)$ \\
Normal weight is important for health & $\begin{array}{l}\text { For overweight and obese patients, even small } \\
\text { weight loss can produce health benefits }\end{array}$
\end{tabular}

*1 response missing.

GPs, general practitioners; PCP, primary care practitioners.

in weight management and monitoring with patients referred to them from GPs. One PN expressed frustration that while GPs were referring patients to them with substantial weight issues, the PN's practice weight management programme was not able to effectively manage those patients (table 5; Quotation 4).

\section{What do PCPs believe are the barriers to weight discussion and management in primary care consultations?}

In questionnaires, PCPs reported lack of patient motivation $(92.8 \%)$, shortage of referral pathways $(57.2 \%)$ and lack of time $(50 \%)$ as frequent barriers to weight discussion and management during consultations. Few PCPs reported lack of training, knowledge, skills and confidence as frequent barriers.

During interviews, PCPs expressed a clear preference for discussing weight issues within the context of patients' existing health issues that could be directly related to weight. PCPs deemed this as an appropriate context to discuss weight because they believed they had the medical evidence to support them and they can also make it clear to the patient why it was relevant to discuss weight (table 5; Quotations 5 and 6).

Conversely, many PCPs expressed an apprehension to start a discussion about patient weight when they could not establish a clear link between existing health issues and the patient's weight, or when patients did not recognise that their body weight was excessive and potentially problematic. Many PCPs perceived that weight was an affective and personal issue for patients and discussing weight without a clear health-related reason was inappropriate and may elicit a negative emotional reaction from patients (table 5; Quotations 7 and 8).

When asked about barriers to weight management, PCPs highlighted the inefficacy of weight management interventions as a barrier, citing examples of their own lack of success with them. Some questioned the evidence base for weight management interventions recommended by clinical guidelines (table 5; Quotation 9).

Systemic barriers to weight management were emphasised by PCPs, including lack of consultation time, and shortage of financial and human resources in primary care. Restrictive eligibility criteria for specialised weight management referrals were also highlighted as a barrier. There was despondency among PCPs that they had nowhere to refer overweight patients when weight was not (yet) impacting on their health, and even when patients had clinical weight issues, they were not eligible for some specialist care (table 5; Quotation 10).

Issues at the policy and management level were discussed. One PCP highlighted that current NHS working contracts did not prioritise or incentivise weight management (table 5; Quotation 11).

Patient-related issues were also perceived as a significant barrier to weight management in primary care. Several PCPs described patients with overweight and obesity as lacking the motivation to address weight issues, and that for many patients their weight was not a priority (table 5 ; Quotation 12).

PCPs acknowledged that training was always potentially useful; however, most were confident in their ability and were ambivalent about receiving additional weight management training. Lack of weight management effectiveness was instead attributed to patient factors, including lack of motivation (table 5; Quotation 13).

\section{DISCUSSION}

This study investigated the perceptions of patients with overweight and obesity, and their PCPs' perceptions of weight and weight management. Our findings suggest that many patients with overweight and obesity have inaccurate perceptions about their body weight and underestimate their risk of developing weight-related health issues. Conversely, PCPs (whom the patients in this study consulted) believed their patients with overweight and obesity were well aware of weight-related health risks. Patients and PCPs agreed that behavioural factors were most important for causing obesity and that medical issues were the most important consequence of obesity. PCPs perceived responsibility to address patient weight issues when they impacted directly on health but did not believe their role was to engage in preventative patient weight management. PCPs identified systemic barriers to weight management, and perceived ineffective weight management interventions and patient factors as significant obstacles to assisting patients with weight issues.

\section{Patient weight and risk misperceptions}

Many patients with overweight and obesity in this sample underestimated their clinically defined weight, confirming previous UK research. ${ }^{37}$ Two-thirds of Scottish adults have overweight, ${ }^{4}$ therefore shifts in societal norms, as overweight becomes the new 'normal', provide a possible explanation for these weight-related misperceptions. ${ }^{20}$ Adults with overweight and who do not accurately perceive their weight engage less in weight management, ${ }^{23}$ highlighting how inaccurate weight perceptions may challenge effective weight management. 
Table 5 Themes and quotations from PCP semi-structured interviews

Theme Quotation

PCP role in patient weight management

1. I have a responsibility to make them aware that (their weight) is an issue where it's clearly impacting on their (health). Do I have a responsibility to assist them with that? If they are looking for that assistance. I would have a responsibility to assist them or signpost them to what can assist them'. (GP 11; male; BMI 26.2)

2. I don't want to be weighing people every week. I don't think that's my role.(...)I think it's also not a good use of our expertise as generalist doctors. I think we've got other things that we could be doing. (GP 6; female; BMI 23.3)

3. Patients need to take some responsibility themselves. And if they know that they're carrying a bit of extra weight, they don't need to see a GP necessarily. (GP 12; female; BMI 24.7)

4. We do have patients referred from the GP with bigger (weight) problems. I think perhaps they say, well that's that problem solved. Whereas(...)we've probably made it worse for that person because(...)we're not offering a solution. (PN 2; female; BMI 29.9)

Discussing weight issues with patients

5. So, I have to say that I tend only to (raise weight for discussion) if I see it as relevant to the problem that they've got. (GP 1; male; BMI 26.2)

6. I can legitimise that conversation (about weight) because l've got evidence here in front of me that helps me with that discussion. (GP 6; female; BMI 23.3)

7. It's when (patients) don't present (weight) as a problem, and clearly, to my mind, it is a gross, elephant in the room, problem. And they don't even want to even pick it up. Then I have a problem. Because it is an invitation for a dysfunctional consultation. (GP 5; male; BMI 23.4)

8. To raise (weight for discussion) completely out of the blue, just because it's on the doctor's agenda, the patient hasn't even invited you to talk about that, what may be a very sensitive aspect of their self-image. I find, I would say, naturally difficult as a human being. (GP 11; male; BMI 26.2)

\begin{tabular}{|c|c|}
\hline $\begin{array}{l}\text { Barriers } \\
\text { to weight } \\
\text { management }\end{array}$ & $\begin{array}{l}\text { 9. The biggest (weight management barrier) is the lack of any good intervention. Say if someone has high } \\
\text { blood pressure, I can give them tablets that will bring it down (or) can give them an injection and make } \\
\text { them better. If someone's got obesity, I'm kind of stuck. I can give them advice on what to do but I don't } \\
\text { feel in many cases, that's terribly helpful or terribly effective. (GP 1; male; BMI 26.2) } \\
\text { 10. Someone with a BMI of 36, won't be referred to a dietician because it's not enough. So, we've got to allow } \\
\text { a problem to become bigger before they get more specialised care. (PN 2; female; BMI 29.9) } \\
\text { 11. (Patients')obesity feeds into (their other health issues), but actually whether or not I do anything about the } \\
\text { obesity makes no difference to whether I've fulfilled my contract, which I've signed with the health board. } \\
\text { (GP 8; male; BMI 25.5) } \\
\text { 12. (Patients') can be helped with (weight issues) if they want to be or they can probably get there themselves } \\
\text { with time and a bit of patience. But I think it is extremely difficult for people who find themselves in poor } \\
\text { housing, they've got limited money, they perhaps feel that they have very little that is going to change } \\
\text { or improve in their lives.(..)You're saying to them, well you could be a few pounds lighter and they're } \\
\text { thinking, well actually, I could be less suicidal. (GP 8; male; BMI 25.5) } \\
\text { 13. I don't feel I'm particularly badly trained in (weight management), but obviously what I'm asking them to } \\
\text { do isn't working. Maybe the way I'm presenting it. I don't think what I'm saying is wrong.(..)It's maybe the } \\
\text { way I present it to them, it's not ticking the right box and motivating them. (GP 2; female; BMI } 22.6 \text { ) }\end{array}$ \\
\hline
\end{tabular}

BMI, body mass index; GP, general practitioner; PCP, primary care practitioner.

Our analysis found that patients who underestimated their weight were more likely to underestimate their risk of weight-related health issues, including type 2 diabetes and cardiovascular disease, reflecting previous findings. ${ }^{30}$ Given the well-established links between excessive weight and these conditions, ${ }^{38} 39$ this finding is concerning. Patients' inaccurate weight-related risk perceptions contrast with PCPs' beliefs that most patients were well aware of the health risks of obesity. The current Scottish government clinical strategy, 'Personalising Realistic Medicine', emphasises shared and informed decision making. ${ }^{40}$ This aims to ensure that patients are fully aware of the risks and benefits to treatment and care decisions, and that health professionals understand and respect patient values. ${ }^{40}$ Inaccurate weight-related perceptions held by many PCPs and their patients may hinder informed decision making about weight management.

\section{Shared PCP and patient beliefs about cause and consequences of obesity}

PCPs and patients shared beliefs that unhealthy behaviours were most important for causing obesity and that medical issues were the most significant consequence of obesity. These findings support previous research where PCPs and patients framed obesity as a consequence of lifestyle choices, as opposed to a medical health issue, ${ }^{41}$ therefore management of obesity should include lifestyle change for all patients, supplemented by medication and/or bariatric surgery in those patients with severe obesity or obesity with complex needs, if required. ${ }^{42}$ Medical professionals 
can perceive lifestyle change as the responsibility of the patient ${ }^{43}$ and do not view excess weight alone as a medical issue. ${ }^{14}$ These perceptions may diminish the role of PCPs in weight management and pass responsibility onto patients, catalysing a barrier to effective patient weight management. Several countries have recognised obesity as a disease, including the USA, Canada and Portugal, while the UK does not currently. ${ }^{44}$ Recognition of obesity as a disease could increase the priority of obesity management within the health service and could enable primary care to focus resource on prevention and develop more effective patient weight management pathways. ${ }^{445}$

\section{PCP beliefs about the role of weight management in primary care}

PCPs perceived that primary care has an essential role in patient weight management, yet they were clear that their role was not the prevention of overweight and obesity. Some PCPs believed patient weight is only the responsibility of primary care when it impacts on patients' health or if patients requested assistance with weight. A thematic synthesis of PCPs weight management beliefs found that PCPs only perceived weight management as their role when it was associated with comorbidities, and that non-symptomatic weight issues were non-medical and therefore not the responsibility of primary care. ${ }^{14}$ Qualitative work from Canada found that primary care patients believed it was the responsibility of family physicians to discuss weight management options with them. ${ }^{46}$ Beliefs that preventative weight management is not the responsibility of primary care are incompatible with clinical guidelines and Scottish Government policy, which prioritise obesity prevention. ${ }^{847} \mathrm{PCPs}$ in this sample highlighted systemic and policy issues, such as lack of incentivisation or contractual obligation to address weight issues, and shortage of preventative referral options for people with overweight and or obesity. These findings therefore highlight a need for a review of current guidelines and policies, and the structure of care pathways, to prioritise and facilitate the implementation of obesity prevention practices within primary care in Scotland.

\section{PCP's perceptions of barriers to weight discussion and patient weight management}

PCPs in this sample highlighted the importance of context when starting a discussion about weight with their patients. PCPs felt supported by medical evidence to discuss weight when it was relevant for patients' existing health issues but were concerned that they may upset patients if they were unable to clearly link weight issues to patients' existing health issues. Previous research has reported that PCPs feel apprehensive about discussing weight issues for fear of upsetting or offending patients. ${ }^{48} 49$ However, research also suggests that few patients perceive that they have been treated disrespectfully by PCPs when discussing weight issues ${ }^{50}{ }^{51} \mathrm{~A}$ recent UK-based obesity intervention trial, whereby PCPs opportunistically (ie, randomly) offered weight management referrals to patients with obesity, concluded that patients welcomed the intervention and $81 \%$ thought it was helpful and appropriate in this context; ${ }^{52}$ however, international evidence suggests that some patients may not view primary care as the most appropriate place to seek weight-related advice and/or management. ${ }^{53} 54$ Additionally, analysis of directly observed weight discussion in primary care, conducted alongside the research reported in this paper, found that patients reduced their uses of emotional expression and responsiveness communication during weight discussion. ${ }^{11}$ Hence, while PCP concerns about upsetting or offending patients by discussing weight was cited as a significant barrier to weight discussion by this sample, the evidence suggests that such concerns may be misplaced.

This study found that PCPs generally had confidence in their own skills and ability to manage patients' weight, however they did not have confidence in the health system to support them in this. PCPs reported that they lacked time or resource to deliver patient weight management effectively and were sceptical about the efficacy of weightrelated advice and signposting, reflecting previous findings. ${ }^{13} 14$ Limited weight management referral options were also a frequently cited barrier by PCPs, which is concordant with a recent review of NHS Scotland weight management provision. ${ }^{55}$ Survey research exploring weight-related beliefs of over 100 PCPs working in Scotland also concluded that time and referral pathways were barriers to weight management, ${ }^{26}$ indicating that these are common barriers to primary care weight management in Scotland.

Lack of patient motivation to lose weight was identified by many PCPs in this study as a barrier to weight management, however previous work has shown that PCPs often underestimate the motivation of people with obesity to lose weight. ${ }^{56}$ Additionally, over $50 \%$ of PCPs in this study agreed with questionnaire statements that it was difficult for patients with overweight and obesity to lose weight and that few patients maintain weight loss. This combined evidence suggests a possible PCP biased belief that patients with obesity lack motivation to engage in weight loss. Health professional assumptions and biases about people with overweight and obesity have been cited by various studies as a potential barrier to effective weight management ${ }^{57-59}$ and may even result in poorer care and outcomes for patients. ${ }^{60}$

PCPs describe a 'catch 22' situation; they perceive many barriers to managing patient weight and regard current patient weight management approaches as ineffective (partly due to patients' lack of willingness to engage) but are unable to offer patients specialist services or referrals due to lack of resource and availability. Qualitative evidence highlights that an educational intervention using a structured communication strategy (Ask, Assess, Advise, Agree and Assist: 5As) for PCPs may help to reduce perceived barriers such as time restriction, bias and interdisciplinary communication related to patient weight management. This was reported to improve PCP 
knowledge about obesity and confidence to discuss and facilitate weight management. ${ }^{61}$

\section{Strengths and limitations}

A novel aspect of this study was that all participating patients were consulted by one of the participating PCPs, allowing more meaningful interpretations of the data. Previous studies examining primary care weight-related beliefs focus only on PCPs or patients; or they compare convenience samples of PCPs and patients who have no direct relationship with each other.

A notable strength of this study was the representative patient sample, in terms of prevalence of patients with overweight. The patient sample in this study underrepresented patients aged $18-24$ years $(6.23 \%$ vs $13.66 \%$ nationally) and over-represented patients aged 65-74 years $(22.30 \%$ vs $12.03 \%$ nationally) when compared with the most recent primary care patient list information from national NHS Scotland statistics. ${ }^{62}$

PNs proved challenging to engage and recruit during this study and were under-represented in this sample. The PNs who did participate in this study perceived themselves to have a more active role in weight management than GPs, suggesting they should be the focus of future research in patient weight management in primary care.

Interviews exploring beliefs about obesity and primary care weight management were not conducted with primary care patients in this study due to the logistics of the data collection procedure within practices. Although the patient questionnaire data were sufficient for the purposes of this study, exploring these complex topics in greater detail with an interview would have provided a more comprehensive insight into the patients' perspective.

\section{CONCLUSION}

While many patients with overweight and obesity underestimated their weight and their risk of developing chronic disease, most PCPs perceived that their patients were aware of their weight issues. This incongruence may perpetuate patients' inaccurate perceptions of their risk of weight-related health consequences. PCPs acknowledged a responsibility for patient weight, however they find it challenging to discuss weight issues with patients and to assist patients with weight management due to systemic and patient-related barriers. PCPs suggest that obesity alone is not an issue for primary care and that current practice is to treat symptomatic obesity rather than prevent obesity in the first instance. Acknowledging a shared responsibility for patient weight, as outlined in 'Practicing Realistic Medicine', ${ }^{63}$ could improve outcomes for patients with overweight and obesity. There is a pressing need to review, standardise and clarify the primary care weight management process in NHS Scotland and move towards a shared responsibility for obesity as a disease.
Contributors This research was part of Dr CTMcH's PhD, supervised by Drs JEC and AHL. All authors contributed significantly to the conceptualisation and design of this research. CTMcH conducted all recruitment, data collection and data analysis. This paper is an adaption of a PhD thesis chapter, originally written by $\mathrm{CTMcH}$. All authors contributed to the editing and reviewing of this paper.

Funding University of St Andrews 600th Anniversary PhD Scholarship.

Competing interests None declared.

Patient consent for publication Not required.

Ethics approval NHS Research Ethics Committee (REC) London-Surrey Borders (Ref: 14/L0/1831) and University of St Andrews Teaching and Research Ethics Committee (UTREC; Ref: MD11485).

Provenance and peer review Not commissioned; externally peer reviewed.

Data availability statement No additional data available.

Open access This is an open access article distributed in accordance with the Creative Commons Attribution Non Commercial (CC BY-NC 4.0) license, which permits others to distribute, remix, adapt, build upon this work non-commercially, and license their derivative works on different terms, provided the original work is properly cited, appropriate credit is given, any changes made indicated, and the use is non-commercial. See: http://creativecommons.org/licenses/by-nc/4.0/.

ORCID iDs

Calum T McHale http://orcid.org/0000-0002-9274-7261

Anita H Laidlaw http://orcid.org/0000-0003-1214-4100

Joanne E Cecil http://orcid.org/0000-0003-4779-6037

\section{REFERENCES}

1 World Health Organisation. Population-Based approaches to childhood obesity prevention, 2012. Available: https://www.who.int/ dietphysicalactivity/childhood/approaches/en/ [Accessed 31 Jan 2019].

2 World Health Organisation. Overweight and obesity - Fact sheet, 2018. Available: http://www.who.int/mediacentre/factsheets/fs311/ en/ [Accessed 07 October 2018].

3 Organisation for Economic Co-operation and Development. Health at a glance: OECD indicators, 2017. Available: https://www.oecdilibrary.org/social-issues-migration-health/health-at-a-glance 19991312 [Accessed 15 Jan 2019].

4 Scottish Government. Obesity Indicators - Monitoring Progress for the Prevention of Obesity Route Map November 2018 report, 2018. Available: https://www.gov.scot/publications/obesity-indicators/ [Accessed 1 Nov 2018].

5 NHS Scotland Information Services Division (ISD). Practice team information (PTI) annual update 2012/13, 2013. Available: https:// www.isdscotland.org/Health-Topics/General-Practice/Publications/ 2013-10-29/2013-10-29-PTI-Report.pdf [Accessed 21 Nov 2018].

6 Twells LK, Bridger T, Knight JC, et al. Obesity predicts primary health care visits: a cohort study. Popul Health Manag 2012;15:29-36.

7 National Institute for Health and Care Excellence (NICE). Obesity: identification, assessment and management - Clinical guideline [CG189], 2014. Available: https://www.nice.org.uk/guidance/cg189

8 Scottish Intercollegiate Guidelines Network (SIGN). 115: Management of Obesity - A national clinical guideline, 2010. Available: https://www.sign.ac.uk/sign-115-management-of-obesity

9 Laidlaw A, McHale C, Locke H, et al. Talk weight: an observational study of communication about patient weight in primary care consultations. Prim Health Care Res Dev 2015;16:309-15.

10 Booth HP, Prevost AT, Gulliford MC. Access to weight reduction interventions for overweight and obese patients in UK primary care: population-based cohort study. BMJ Open 2015;5:e006642.

$11 \mathrm{McHale}$ CT, Cecil JE, Laidlaw AH. An analysis of directly observed weight communication processes between primary care practitioners and overweight patients. Patient Educ Couns 2019;102:2214-22.

12 Sonntag U, Brink A, Renneberg B, et al. GPs' attitudes, objectives and barriers in counselling for obesity--a qualitative study. Eur J Gen Pract 2012;18:9-14.

13 Claridge R, Gray L, Stubbe M, et al. General practitioner opinion of weight management interventions in New Zealand. J Prim Health Care 2014;6:212-20.

14 Dewhurst A, Peters S, Devereux-Fitzgerald A, et al. Physicians' views and experiences of discussing weight management within routine clinical consultations: a thematic synthesis. Patient Educ Couns 2017;100:897-908. 
15 Al-Ghawi A, Uauy R. Study of the knowledge, attitudes and practices of physicians towards obesity management in primary health care in Bahrain. Public Health Nutr 2009;12:1791-8.

16 Bocquier A, Verger P, Basdevant A, et al. Overweight and obesity: knowledge, attitudes, and practices of general practitioners in France. Obes Res 2005;13:787-95.

17 Brown I, Thompson J. Primary care nurses' attitudes, beliefs and own body size in relation to obesity management. $J$ Adv Nurs 2007;60:535-43.

18 Johnson F, Beeken RJ, Croker H, et al. Do weight perceptions among obese adults in Great Britain match clinical definitions? analysis of cross-sectional surveys from 2007 and 2012. BMJ Open 2014;4:e005561.

19 Burke MA, Heiland FW, Nadler CM. From "overweight" to "about right": evidence of a generational shift in body weight norms. Obesity 2010;18:1226-34.

20 Robinson E. Overweight but unseen: a review of the underestimation of weight status and a visual normalization theory. Obes Rev 2017;18:1200-9.

21 Winter J, Wuppermann A. Do they know what is at risk? health risk perception among the obese. Health Econ 2014;23:564-85.

22 Schwarzer R, Lippke S, Luszczynska A. Mechanisms of health behavior change in persons with chronic illness or disability: the health action process approach (HAPA). Rehabil Psychol 2011;56:161-70.

23 Duncan DT, Wolin KY, Scharoun-Lee M, et al. Does perception equa reality? weight misperception in relation to weight-related attitudes and behaviors among overweight and obese us adults. Int J Behav Nutr Phys Act 2011;8:20.

24 Phelan SM, Burgess DJ, Yeazel MW, et al. Impact of weight bias and stigma on quality of care and outcomes for patients with obesity. Obesity Reviews 2015;16:319-26.

25 Mercer SW, Tessier S. A qualitative study of general practitioners and practice nurses' attitudes to obesity management in primary care. Health Bull 2001;59:248-53.

26 Laidlaw A, Napier C, Neville F, et al. Talking about weight talk: primary care practitioner knowledge, attitudes and practice. $J$ Commun Healthc. In Press 2019;12:145-53.

27 Creswell JW. Research design: qualitative, quantitative, and mixed methods approaches. Sage publications, 2013.

28 Onwuegbuzie AJ, Collins KM. A typology of mixed methods sampling designs in social science research. The qualitative report 2007;12:281-316.

29 Gill P, Stewart K, Treasure E, et al. Methods of data collection in qualitative research: interviews and focus groups. Br Dent $\mathrm{J}$ 2008;204:291-5.

30 Darlow S, Goodman MS, Stafford JD, et al. Weight perceptions and perceived risk for diabetes and heart disease among overweight and obese women, Suffolk County, New York, 2008. Prev Chronic Dis 2012;9:110185

31 Renner B, Schwarzer R. Risk and Health Behaviours: Documentation of the Scales of the Research Project: "Risk Appraisal Consequences in Korea", 2005. Available: http://www.gesundheitsrisiko.de/docs/ RACKEnglish.pdf [Accessed 5th May 2014].

32 Ogden J, Bandara I, Cohen H, et al. General practitioners' and patients' models of obesity: whose problem is it? Patient Educ Couns 2001;44:227-33.

33 World Health Organisation. Body mass index - BMI, 2019. Available: http://www.euro.who.int/en/health-topics/disease-prevention/ nutrition/a-healthy-lifestyle/body-mass-index-bmi [Accessed $19 \mathrm{Dec}$ 2019].

34 Little RJA. A test of missing completely at random for multivariate data with missing values. J Am Stat Assoc 1988;83:1198-202.

35 Braun V, Clarke V. Using thematic analysis in psychology. Qual Res Psychol 2006;3:77-101.

36 QRS International. NVivo QDA [Version 11.4], 2017. Available: https:// www.qsrinternational.com/nvivo/home

37 Robinson E, Oldham M. Weight status misperceptions among UK adults: the use of self-reported vs. measured BMI. BMC Obes 2016;3:21.

38 Abdullah A, Peeters A, de Courten M, et al. The magnitude of association between overweight and obesity and the risk of diabetes: a meta-analysis of prospective cohort studies. Diabetes Res Clin Pract 2010;89:309-19.

39 Fan J, Song Y, Chen Y, et al. Combined effect of obesity and cardio-metabolic abnormality on the risk of cardiovascular disease: a meta-analysis of prospective cohort studies. Int $\mathrm{J}$ Cardiol 2013;168:4761-8.

40 Scottish Government. Personalising realistic medicine: chief medical officer for Scotland's annual report 2017-2018, 2019. Available: https://www.gov.scot/publications/personalising-realistic-medicinechief-medical-officer-scotland-annual-report-2017-2018/ [Accessed 25 Apr 2019].

41 Ogden J, Flanagan Z. Beliefs about the causes and solutions to obesity: a comparison of GPs and lay people. Patient Educ Couns 2008;71:72-8.

42 National Institute for Health and Care Excellence (NICE). Nice pathways: obesity management in adults, 2019. Available: http:// pathways.nice.org.uk/pathways/obesity [Accessed 06 Feb 2020].

43 Chisholm A, Hart J, Lam V, et al. Current challenges of behavior change talk for medical professionals and trainees. Patient Educ Couns 2012;87:389-94.

44 The Lancet Diabetes Endocrinology. Should we officially recognise obesity as a disease? Lancet Diabetes Endocrinol 2017;5:483.

45 Jastreboff AM, Kotz CM, Kahan S, et al. Obesity as a disease: the obesity Society 2018 position statement. Obesity 2019;27:7-9.

46 Torti J, Luig T, Borowitz M, et al. The 5As team patient study: patient perspectives on the role of primary care in obesity management. BMC Fam Pract 2017;18:19.

47 Scottish Government. Preventing overweight and obesity in Scotland: a route MAP towards healthy weight, 2010. Available: http://www.gov.scot/Publications/2010/02/17140721/0

48 Michie S. Talking to primary care patients about weight: a study of GPs and practice nurses in the UK. Psychol Health Med 2007:12:521-5.

49 Blackburn M, Stathi A, Keogh E, et al. Raising the topic of weight in general practice: perspectives of GPs and primary care nurses. BMJ Open 2015;5:e008546.

50 Anderson DA, Wadden TA. Bariatric surgery patients' views of their physicians' weight-related attitudes and practices. Obes Res 2004;12:1587-95.

51 Wadden TA, Anderson DA, Foster GD, et al. Obese women's perceptions of their physicians' weight management attitudes and practices. Arch Fam Med 2000;9:854-60.

52 Aveyard P, Lewis A, Tearne S, et al. Screening and brief intervention for obesity in primary care: a parallel, two-arm, randomised trial. Lancet 2016;388:2492-500.

53 Tan D, Zwar NA, Dennis SM, et al. Weight management in general practice: what do patients want? Med J Aust 2006;185:73-5.

54 Tham M, Young D. The role of the General Practitioner in weight management in primary care--a cross sectional study in General Practice. BMC Fam Pract 2008;9:66.

55 Read S, Logue J. Variations in weight management services in Scotland: a national survey of weight management provision. $J$ Public Health 2016;38:e325-35.

56 Befort CA, Greiner KA, Hall S, et al. Weight-Related perceptions among patients and physicians: how well do physicians judge patients motivation to lose weight? J Gen Intern Med 2006;21:1086-90.

57 Dixon JB, Hayden MJ, O'Brien PE, et al. Physician attitudes, beliefs and barriers towards the management and treatment of adult obesity: a literature review. Aust J Prim Health 2008;14:9-18.

58 Foster GD, Wadden TA, Makris AP, et al. Primary care physicians' attitudes about obesity and its treatment. Obes Res 2003;11:1168-77.

59 Khandalavala BN, Rojanala A, Geske JA, et al. Obesity bias in primary care providers. Fam Med 2014;46:532-5.

60 Phelan SM, Burgess DJ, Yeazel MW, et al. Impact of weight bias and stigma on quality of care and outcomes for patients with obesity. Obes Rev 2015;16:319-26.

61 Asselin J, Salami E, Osunlana AM, et al. Impact of the 5As team study on clinical practice in primary care obesity management: a qualitative study. CMAJ Open 2017;5:E322-9.

62 NHS Scotland Information Services Division (ISD). GP workforce and practice populations, 2017. Available: https://www.isdscotland. org/Health-Topics/General-Practice/Workforce-and-PracticePopulations/ [Accessed 3 May 2017].

63 Scottish Government. Practising realistic medicine: chief medical officer for Scotland annual report, 2018. Available: https://www.gov. scot/publications/practising-realistic-medicine/ [Accessed 11 Jan 2019]. 